\title{
Synthesis, structure and some properties of zirconium phosphate/ oxide support compositions
}

\author{
V. Sydorchuk $\cdot$ W. Janusz $\cdot$ S. Khalameida $\cdot$ \\ E. Skwarek · J. Skubiszewska-Zięba • \\ R. Leboda $\cdot$ V. Zazhigalov
}

ICVMTT2011 Conference Special Chapter

(c) The Author(s) 2011. This article is published with open access at Springerlink.com

\begin{abstract}
Deposited zirconium phosphate samples on the base of silica and titania have been prepared using the sol-gel and mechanochemical methods. Porous structure, phase composition, and electrokinetic parameters have been studied by means of nitrogen adsorption-desorption, XRD, DTA-TG, FTIR, electrophoresis, and potentiometric titration. The compositions possess varied parameters of porous structure, structure of deposited phase, and electrokinetic properties depending on support nature and synthesis conditions.
\end{abstract}

Keywords Zirconium phosphate/oxide support .

Synthesis $\cdot$ Mechanochemical $\cdot$ Zeta potential

\section{Introduction}

Acid salts of quadrivalent metals are the most frequently studied groups of inorganic exchangers [1,2]. Amorphous and crystalline zirconium phosphates $\mathrm{Zr}\left(\mathrm{HPO}_{4}\right)_{2} \cdot(\mathrm{ZrP})$ also belong to this class and possess both its advantages and shortcomings [3-5]. Due to the high Bronsted acidity they are promising as acidic catalysts, adsorbents of cations, solid

V. Sydorchuk · S. Khalameida $\cdot$ V. Zazhigalov Institute for Sorption and Problems of Endoecology, NAS of Ukraine, 13 Naumov Str, Kiev 03164, Ukraine

W. Janusz $(\bowtie) \cdot$ E. Skwarek

Department of Radiochemistry and Colloid Chemistry, Maria Curie-Skłodowska University, Maria Curie-Sklodowska Sq. 3, 20-031 Lublin, Poland

e-mail: wladyslaw.janusz@poczta.umcs.lublin.pl

J. Skubiszewska-Zięba · R. Leboda

Faculty of Chemistry, Maria Curie-Sklodowska University,

Maria Curie-Sklodowska Sq. 3, 20-031 Lublin, Poland electrolytes, supports of the active phase [6-8] i.e., multifunctional materials. Besides, $\mathrm{ZrP}$ is characterized by large thermal and chemical stability, resistance to ionizing radiation. As for its ion-exchange properties, $\mathrm{ZrP}$ is insoluble in water, of large capacity, fast kinetics, and superior to organic exchangers. However, ZrP, first of all crystalline substances, exists as submicron particles and cannot be directly used in fixed-bed columns or any other flow-through systems because of the excessive pressure drops. Furthermore, crystalline $\mathrm{ZrP}$ has a low specific surface area. In contrast, amorphous $\mathrm{ZrP}$ is characterized by larger specific surface area and sufficiently large content of micropores which impairs its kinetic characteristics and reduces the efficiency of its application in sorption and catalysis.

To overcome these drawbacks several ways have been suggested. The deposition onto granular supports with a large specific surface area and porosity is one of the most effective methods to improve $\mathrm{ZrP}$ properties. Among the used carriers, organic polymers can be as primarily identified [9-11]. At the same time, it is known that inorganic porous materials possess greater mechanical strength and do not swell in liquid media. Therefore, they are preferred as supports. Different silicas are most often used as matrices for $\mathrm{ZrP}[2,12-21]$. There are some examples of the application of other inorganic materials as carriers for $\mathrm{ZrP}$ : active carbon [22], ceramic [23], alumina [24].

Liquid grafting to the silica surface, exfoliation of crystalline forms of $\mathrm{ZrP}$ by different silanes, and precipitation of $\mathrm{ZrP}$ on outer and inner surfaces of supports are used as a rule of deposited $\mathrm{ZrP}$, synthesis. Only one work is devoted to ball milling procedure, namely for deposition of $\mathrm{ZrP}$ onto alumina carrier [24].

The content of deposited or incorporated $\mathrm{ZrP}$ in compositions is varied between 10 and 50\% w/w and depends on the distribution process. On the other hand, their 
physico-chemical properties are also determined by the fraction of $\mathrm{ZrP}$ in the composition. For example, according to [14], deposited ZrP showed a maximum of ion-exchange capacity with the $\mathrm{ZrP}$ content about $20 \% \mathrm{w} / \mathrm{w}$ whereas the conductivity has the maximum at $25 \% \mathrm{w} / \mathrm{w}$. The last maximum is located with $20-30 \%$ w/w of inorganic oxides according the data in [24]. As a rule, the specific surface area of the silica based compositions is increased with increasing $\mathrm{ZrP}$ percentage [14] or passes through a maximum at $21 \% \mathrm{w} / \mathrm{w}$ of $\mathrm{ZrP}$ [18]. On the other hand, the specific surface area of $\gamma-\mathrm{ZrP}$ in the composition with silica increases from a few $\mathrm{m}^{2} \mathrm{~g}^{-1}$ to $191 \mathrm{~m}^{2} \mathrm{~g}^{-1}$, as a result of exfoliation [17]. This $\gamma-\mathrm{ZrP} / \mathrm{SiO}_{2}$ composite exhibited a higher conversion rate of ethylbenzene to styrene (about five times) compared with bulk un-exfoliated $\gamma$-ZrP.

Literature review points out to the enhancement of physico-chemical characteristics of supported $\mathrm{ZrP}$ and the prospects of its use in catalytic, adsorption, and other processes. However, the studies are not systematic. Therefore, from our point of view, it is necessary to develop other approaches for its preparation and extend the number of potential supports.

In this study, we propose some new procedures for synthesis of deposited $\mathrm{ZrP}$ :

- application of dry and wet mechanochemical deposition;

- deposition of $\mathrm{ZrP}$ in the form of dried xerogel and wet hydrogel;

- sol-gel co-precipitation of silica and ZrP by orthophosphoric acid;

- use of fumed oxides (silica and titania) as supports.

The investigation of some physico-chemical properties of the prepared deposited samples (specific surface area and porosity, surface structure, and electrokinetics) is another task of the presented study.

\section{Experimental}

\section{Reagents}

Fumed silica (aerosils A50 and A380) and titania (Oriana, Ukraine) with the specific surface area 45, 346, and $64 \mathrm{~m}^{2} \mathrm{~g}^{-1}$, respectively, were utilized as supports for preparation of deposited samples. Aerosils are amorphous and titania consists of phases of anatase and rutile.

Synthesis procedures

The procedures of $\mathrm{ZrP}$ deposition $(20 \% \mathrm{w} / \mathrm{w})$ were as follows:
(1) Sol-gel co-precipitation, $4.427 \mathrm{~g}$ of $\mathrm{ZrOCl}_{2} \cdot 8 \mathrm{H}_{2} \mathrm{O}$ were dissolved in $16.5 \mathrm{~mL}$ of water (solution 1). $40.5 \mathrm{~mL}$ of TEOS were mixed with $18 \mathrm{~mL}$ ethanol while stirring for $10 \mathrm{~min}$ (solution 2). Solution 1 was added dropwise to solution 2 while stirring for $10 \mathrm{~min}$ (mixed solution 3). $19 \mathrm{~mL}$ of $1 \mathrm{M}$ aqueous solution of orthophosphoric acid dropwise were added to mixed solution 3 for $10 \mathrm{~min}$. Then agitation stopped. Hydrogel was formed for $10 \mathrm{~min}$. It was aged at $20{ }^{\circ} \mathrm{C}$ for $20 \mathrm{~h}$. Then the aged gel was washed with water until the absence of $\mathrm{Cl}^{-}$ions in the rinsing water and dried in air at $20{ }^{\circ} \mathrm{C}$ for $72 \mathrm{~h}$. The part of washed wet gel was subjected to hydrothermal treatment (HTT) at $200{ }^{\circ} \mathrm{C}$ for $3 \mathrm{~h}$.

(2) Appropriate amounts of reagents, namely $\mathrm{ZrP}$ dried xerogel or hydrogel with $88 \% \mathrm{w} / \mathrm{w}$ humidity and fumed titania or aerosils A-50 (A-380), were subjected to mechanochemical treatment MChT (milling) at $300 \mathrm{rpm}$ for $0.5 \mathrm{~h}$ using Pulverisette-7 (Fritsch Gmbh). The milling was carried out in air (dry milling) or in water (wet milling). Water was not added to the mill when ZrP hydrogel was used. The bulk $\mathrm{ZrP}$, that used while milling, was prepared through precipitation of $\mathrm{H}_{3} \mathrm{PO}_{4}$ with aqueous solutions of $\mathrm{ZrOCl}_{2} \cdot 8 \mathrm{H}_{2} \mathrm{O}$ as in p. 1 . The formed colloids after wet milling were dried at $20{ }^{\circ} \mathrm{C}$ for $72 \mathrm{~h}$.

\section{Study of physico-chemical characteristics}

The starting reagents and products of their mechanochemical transformations were studied by means of X-ray powder diffraction (XRD) using a diffractometer Philips PW 1830 with $\mathrm{CuK}_{\alpha}$-radiation. The DTA and TG curves were recorded using the apparatus Derivatograph-C (F.Paulik, J.Paulik, L.Erdey) in the temperature range 20-700 ${ }^{\circ} \mathrm{C}$ at the heating rate $10{ }^{\circ} \mathrm{C} \mathrm{min}^{-1}$. The FTIR spectra in the range $4000-400 \mathrm{~cm}^{-1}$ were registered using the spectrometer "Spectrum-One" (Perkin-Elmer). The ratio of sample and $\mathrm{KBr}$ powders was $1: 20 . \mathrm{KBr}$ was dried at $600{ }^{\circ} \mathrm{C}$ for $2 \mathrm{~h}$ before measurements.

The parameters of porous structure (specific surface area $S$, sorption pore volume $V_{\mathrm{s}}$, micropores volume $V_{\mathrm{mi}}$, mesopores volume $V_{\mathrm{me}}$ ) were determined from the isotherms of low-temperature nitrogen adsorption obtained by means of the analyzer ASAP $2405 \mathrm{~N}$ ("Micromeritics Instrument Corp"). Outgassing temperature and duration were $150{ }^{\circ} \mathrm{C}$ and $2 \mathrm{~h}$, respectively. Meantime, the value of $V_{\mathrm{s}}$ was determined with the relative nitrogen pressure close to 1 , the values of $V_{\mathrm{mi}}$ and $V_{\mathrm{me}}$ were calculated using the $\mathrm{t}$ method and BJH-method, respectively. The total pore volume $V_{\Sigma}$ was determined by impregnation of the 
samples, dried at $150{ }^{\circ} \mathrm{C}$, by liquid water. The following relations are valid between these parameters:

$V_{\mathrm{s}}=V_{\mathrm{mi}}+V_{\mathrm{me}}$

$V_{\Sigma}=V_{\mathrm{s}}+V_{\mathrm{ma}}$,

where $V_{\mathrm{ma}}$ - the volume of macropores which are not filled in the process of adsorption from the vapor phase, but by impregnation from the liquid phase.

The pore diameter $d_{\mathrm{PSD}}$ was calculated from the curves of pore size distribution (PSD) using the desorption branch of isotherms accordingly to the $\mathrm{BJH}$-method.

Electrokinetic measurements

Electrophoresis studies were carried out using a Zetasizer 3000 (Malvern Instruments). The suspensions of oxide (100 ppm of solid) were prepared using an ultrasonic disperser (Sonicator Misonix Inc.) before the electrokinetic measurements. The zeta potential $\zeta$ of the system has been determined as a function of $\mathrm{pH}$ for $0.001 \mathrm{~mol} \mathrm{dm}^{-3}$ solution of $\mathrm{NaCl}$. The $\mathrm{pH}$ values, measured by a precision digital $\mathrm{pH}$ meter, were adjusted by the addition of $0.1 \mathrm{~mol} \mathrm{dm}^{-3} \mathrm{HCl}$ or $\mathrm{NaOH}$ solutions. The zeta potential was calculated from electrophoretic mobility using the Smoluchowski equation.

\section{Determination of surface charge density}

The surface charge of titanium dioxide was calculated by comparison of the potentiometric titrations curve of the oxide suspension and the background electrolyte. These titrations of $\mathrm{ZrP}$ suspensions in $0.001 \mathrm{~mol} \mathrm{dm}^{-3}$ solution of $\mathrm{NaCl}$ were carried out in the thermostatic Teflon vessel, under nitrogen atmosphere free of $\mathrm{CO}_{2}$, at $25{ }^{\circ} \mathrm{C}$. Measurements were performed using a PHM 240 Radiometer Research $\mathrm{pH}$ meter with $\mathrm{K} 401$ as a glass electrode and G202B as a calomel reference electrode. Potentiometric titration was carried out with the use of automatic burette Dosimat (Metrohm). The point zero of charge was determined from of surface charge density as a function of $\mathrm{pH}$, $\mathrm{pH}_{\mathrm{pzc}}$ was equal to $\mathrm{pH}$, when $\sigma_{0}=0$.

\section{Results and discussion}

\section{Porous structure of compositions}

The isotherms of nitrogen adsorption-desorption for the deposited samples prepared using different methods are presented in Figs. 1, 2, and 3. The parameters of porous structure which were calculated from the adsorptiondesorption isotherms are presented in Table 1. One can see that the initial bulk $\mathrm{ZrP}$ is micro-mesoporous (sample 1). Its dry mechanochemical deposition in the form of xerogel on aerosil A-380 leads to the increase of specific surface area of the resulted composition (sample 2). However, this sample can be considered as non-porous because initial support (A-380) itself is superfine and non-porous and remains in that state in the process of dry milling [25]. The use of a more coarse dispersed support, namely fumed $\mathrm{TiO}_{2}$, results in formation of rigid porous compositions as a result of dry and wet milling (samples 3,4 ). In both cases milled samples contain mesopores with two maxima in the same position which are observed on the PSD curves. It can be seen that the PSD curve, showing the characteristic of the sample prepared by wet milling, has no sharp peaks. At the same time, the fraction of mesopores (column 6) for this sample is small (about 16\%) but the content of macropores is prevalent (column 8). Because of this its specific surface area is three times lower compared with that of the sample subjected to dry milling. It should be noted that isotherms of nitrogen adsorption-desorption obtained for the compositions, based on titania, contain a weakly pronounced capillar-condensation hysteresis loop (Fig. 1). Deposition of $\mathrm{ZrP}$ in the form of wet hydrogel leads to formation of meso-macroporous compositions with different contents of indicated pores and high value of total pore volume (samples 5-7). Meantime, the sample based on more dispersed A380 possesses maximal value of $V_{\text {me }}$ while that prepared from lesser dispersed A50 has a maximal value of $V_{\mathrm{ma}}$. The isotherms obtained for the compositions prepared from $\mathrm{ZrP}$ hydrogel relate to type IV and contain a capillar-condensation hysteresis loop of type A (Figs. 1,2). It is noteworthy that the PSD curve for the composition based on A380 has one maximum but those for the samples based on lesser dispersed $\mathrm{A} 50$ and $\mathrm{TiO}_{2}$ possess two maxima (Figs. 1, 2). The latter is better than for the sample on the basis of $\mathrm{TiO}_{2}$ (Fig. 1 curve c).

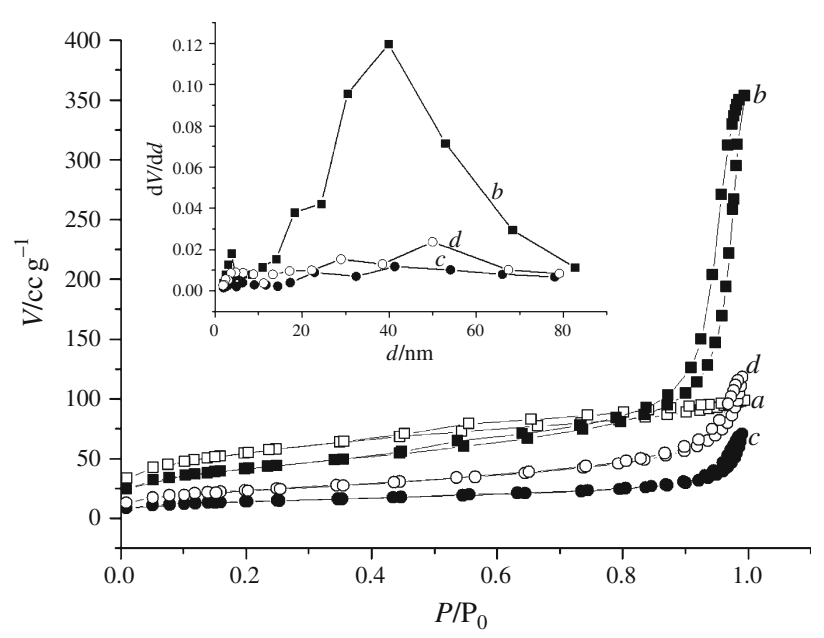

Fig. 1 Isotherms of nitrogen adsorption-desorption and curves of PSD for the bulk $\mathrm{ZrP}(a)$ and the milled samples based on $\mathrm{TiO}_{2}: \mathrm{ZrP}$ xerogel air $(b), \mathrm{ZrP}$ xerogel water $(c), \mathrm{ZrP}$ hydrogel $(d)$ 


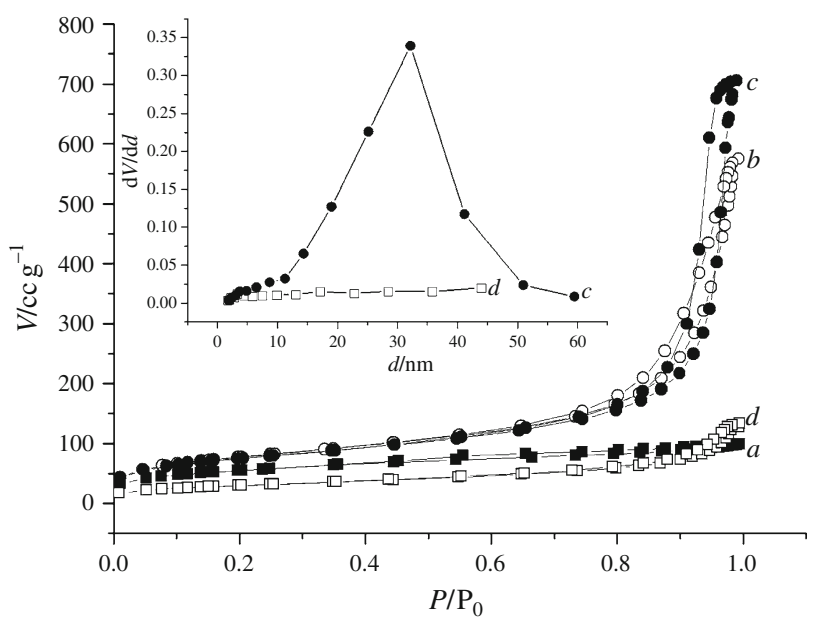

Fig. 2 Isotherms of nitrogen adsorption-desorption and curves of PSD for the bulk $\mathrm{ZrP}(a)$ and the milled samples based on aerosils: $\mathrm{ZrP}$ xerogel air on $\mathrm{A} 380(b), \mathrm{ZrP}$ hydrogel on A380 (c), ZrP hydrogel on $\mathrm{A} 50(d)$

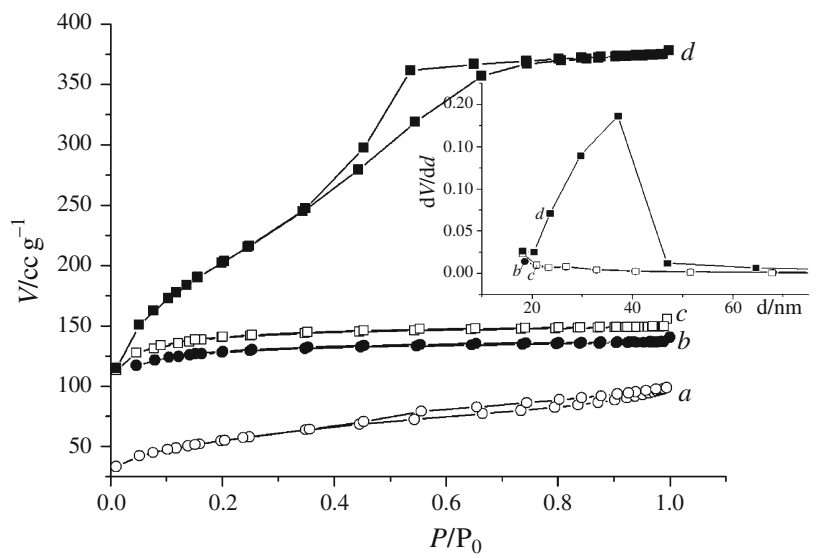

Fig. 3 Isotherms of nitrogen adsorption-desorption and curves of PSD for the bulk $\mathrm{ZrP}(a)$ and the samples prepared via the sol-gel method: $10 \% \mathrm{w} / \mathrm{w} \mathrm{ZrP}$ at $20{ }^{\circ} \mathrm{C}(b), 20 \% \mathrm{w} / \mathrm{w} \mathrm{ZrP}$ at $20{ }^{\circ} \mathrm{C}(c)$, and $200{ }^{\circ} \mathrm{C}(d)$

It can also be seen that embedding of $\mathrm{ZrP}$ moieties in the siliceous framework in the stage of gelation results in decrease of both specific surface area $\mathrm{S}$ and volume of sorption pores $V_{\mathrm{s}}$, and micropores $V_{\mathrm{mi}}$ (samples 8,9 in comparison with sample 11). In fact, the mesopores volume and size ( $V_{\mathrm{me}}$ and $d_{\mathrm{PSD}}$, respectively) as well as the total pore volume $V_{\Sigma}$ are not changed. However, the value of $V_{\Sigma}$ exceeds that of $V_{\mathrm{s}}$. The latter indicates formation of macropores in the composite samples. Soft HTT in the hydrogel stage unexpectedly leads to the sharp growth of $S$, $V_{\mathrm{s}}, V_{\mathrm{me}}$, and $V_{\Sigma}$ (sample 10). At the same time, micropores almost disappear. In other words, more open and larger porous, namely mesoporous, structure, which is more accessible for sorbate molecules, is formed. This can be seen from the change of the shape of adsorption-desorption isotherms (Fig. 3) and the curves of PSD that are constructed based on the isotherms (Fig. 3). Indeed, the curves of PSD for untreated samples 8 and 9 have a broad maximum around $2.7 \mathrm{~nm}$, while a distinct peak at $3.7 \mathrm{~nm}$ is on the PSD curve for modified sample 10.

It should be added that the above-described patterns of change of the porous structure largely coincide with those previously obtained for the heteropolycompounds/oxide supports compositions [26, 27].

\section{Structure of deposited samples}

In accordance with the X-ray fluorescent analysis, bulk and deposited $\mathrm{ZrP}$ has the atom ratio $\mathrm{Zr} / \mathrm{P}=2: 1$, which corresponds to the compound $\mathrm{Zr}\left(\mathrm{HPO}_{4}\right)_{2}$. The XRD data show that all supported samples synthesized based on silica are $\mathrm{X}$-ray amorphous. At the same time, diffractograms of the samples based on fumed titania contain reflexes attributed to anatase and rutile, i.e., they relate only to support. In fact, intensity of the reflections of support and their ratios somewhat differ for the prepared compositions. Therefore, all deposited samples contain amorphous $\mathrm{Zr}\left(\mathrm{HPO}_{4}\right)_{2}$. It should be added that initial bulk $\mathrm{ZrP}$ is also $\mathrm{X}$-ray amorphous. The DT- and TG analyses indicate thermal stability of the amorphous component up to $800{ }^{\circ} \mathrm{C}$. The DTA and TG curves obtained for the deposited samples show only the final effect of adsorbed water removal in the temperature range $20-200{ }^{\circ} \mathrm{C}$ and have no effects related to phase transformations.

The FTIR spectra depicted in Figs. 4, 5, and 6 confirm the presence of $\mathrm{ZrP}$ in the structure of compositions. Thus, the spectrum of bulk $\mathrm{ZrP}$ contains a. and b. centered around 425 , 510, 595, 710, and $1038 \mathrm{~cm}^{-1}$ (Fig. 4, curve a) which are attributed to deformation and stretching vibrations of $\mathrm{P}-\mathrm{O}$ bonds in $\mathrm{PO}_{4}{ }^{3-}[4,28,29]$. The embedding of $\mathrm{ZrP}$ into the siliceous framework during the sol-gel synthesis results in shift of a.b. 510 to $528 \mathrm{~cm}^{-1}$ and a.b. $1038 \mathrm{~cm}^{-1}$ toward $980 \mathrm{~cm}^{-1}$ (Fig. 4, curve b). The latter may be a consequence of the interaction between $\mathrm{ZrP}$ and the surface groups of support in narrow pores the content of which is the largest in this sample. The changes of position of indicated a.b. are smaller and lesser for samples prepared at $200{ }^{\circ} \mathrm{C}$ (curve c): thus, a.b. $1038 \mathrm{~cm}^{-1}$ shifts to $1000 \mathrm{~cm}^{-1}$. The latter may be because of the fact that the hydrothermally modified sample possesses larger pores as mentioned above.

In contrast, interaction of deposited $\mathrm{ZrP}$ with nonporous fumed oxides obviously is minimal. At least, this interaction does not appear in spectra of the samples synthesized via milling (Figs. 5, 6): the shift of a. and b. which are characteristic of $\mathrm{ZrP}$ is not observed. Moreover, these bands are overlapped by the intense absorption which is attributed to supports. This can be explained by larger porous structure of the matrices, which are formed from fumed oxides compared with the samples prepared 
Table 1 Influence of synthesis conditions on porous structure resulted compositions

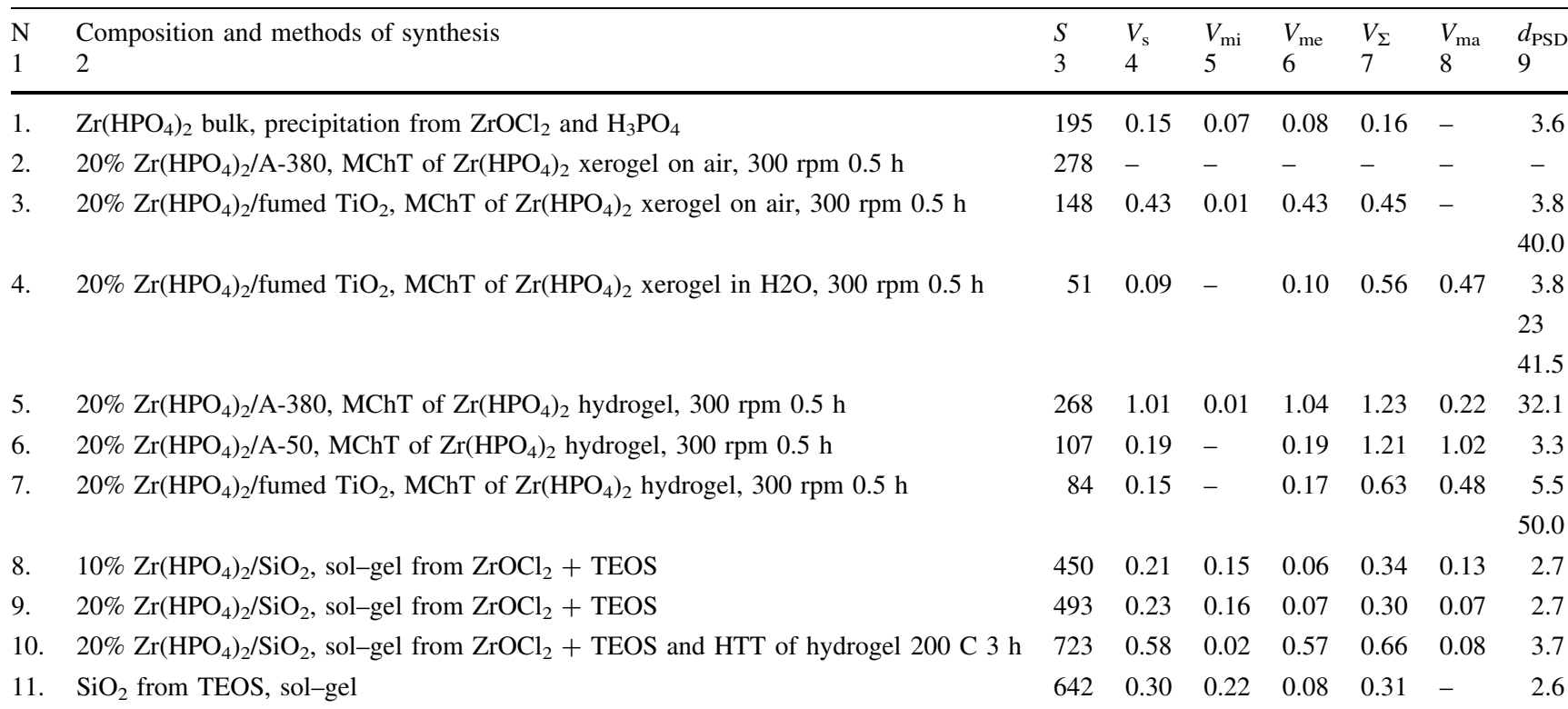

The values of specific surface area, pore volume, and pore diameter in table are given in $\mathrm{m}^{2} \mathrm{~g}^{-1}, \mathrm{~cm}^{3} \mathrm{~g}^{-1}$, and nm, respectively

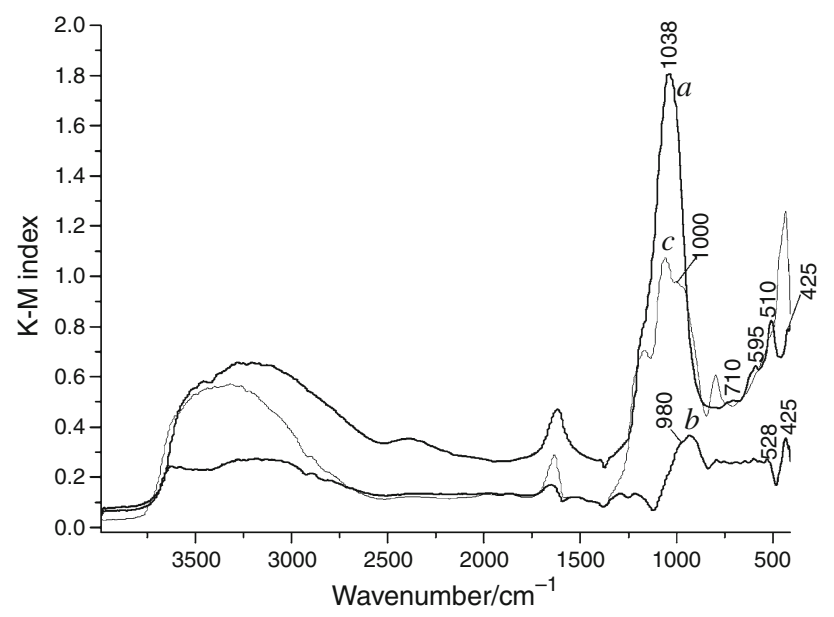

Fig. 4 FTIR spectra for bulk $\operatorname{ZrP}(a)$ and the deposited samples prepared via the sol-gel method at $20^{\circ} \mathrm{C}(b), 200{ }^{\circ} \mathrm{C}(c)$

via the sol-gel route. This can be clearly seen in Table 1 (column 9).

\section{Electrokinetic properties}

Very important parameters characterizing the electric double layer are isoelectric point $\mathrm{pH}_{\text {iep }}$ and point of zero charge $\mathrm{pH}_{\mathrm{pzc}}$. Assuming that the potential of diffuse layer equals the zeta potential, the concentration of surface groups negatively charged in $\mathrm{pH}_{\text {iep }}$ point equals of surface groups which are positively charged. $\mathrm{pH}_{\text {iep }}$ of bulk and some supported $\mathrm{ZrP}$ as a function of $\mathrm{pH}$ in the $0.001 \mathrm{M}$ aqueous $\mathrm{NaCl}$ solution is depicted in Figs. 7, 8. The values of $\mathrm{pH}_{\text {iep }}$ determined for all samples are collected in

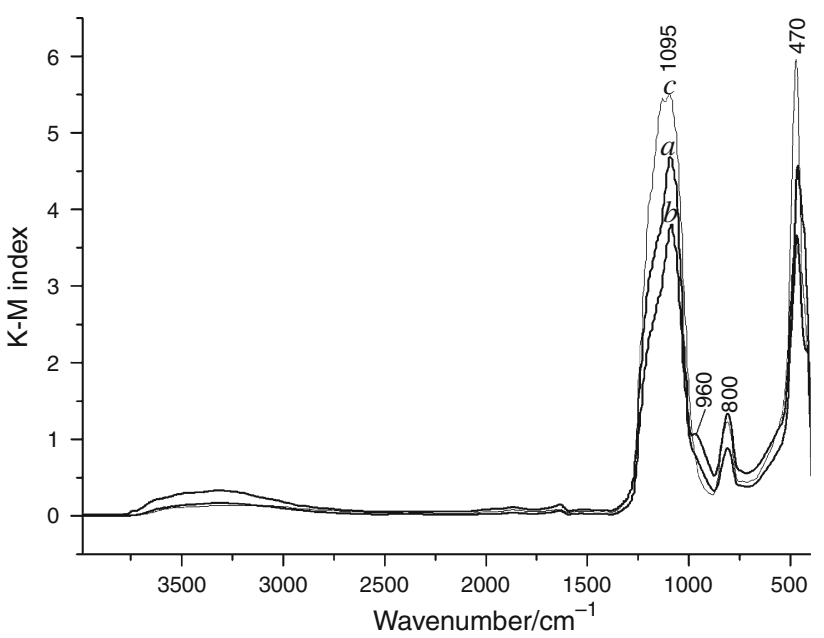

Fig. 5 FTIR spectra for the milled deposited samples based on aerosils: ZrP xerogel air on A380 (a), ZrP hydrogel on A380 (b), and A50 (c)

Table 2. As can be seen a zeta potential reduces with the $\mathrm{pH}$ increase in all cases. It has been also found that nature of support and procedure of $\mathrm{ZrP}$ deposition have great influence on $\mathrm{pH}_{\mathrm{iep}}$ value. The differences between the samples are expressed as in the course of zeta potential- $\mathrm{pH}$ depencence and in the position of the isoelectric point.

The value of $\mathrm{pH}_{\text {iep }}$ for bulk $\mathrm{ZrP}$ equal to 3.65 is consistent with literature [30]. For pure supports prepared under the same conditions, as deposited samples, $\mathrm{pH}_{\text {iep }}$ has the following positions: 2.02, 2.30, 2.61, and 2.53 for milled A380, A50, titania and silica synthesized using the sol-gel technique, respectively. The presented values also correspond to literature data [30, 31]. It is known that 


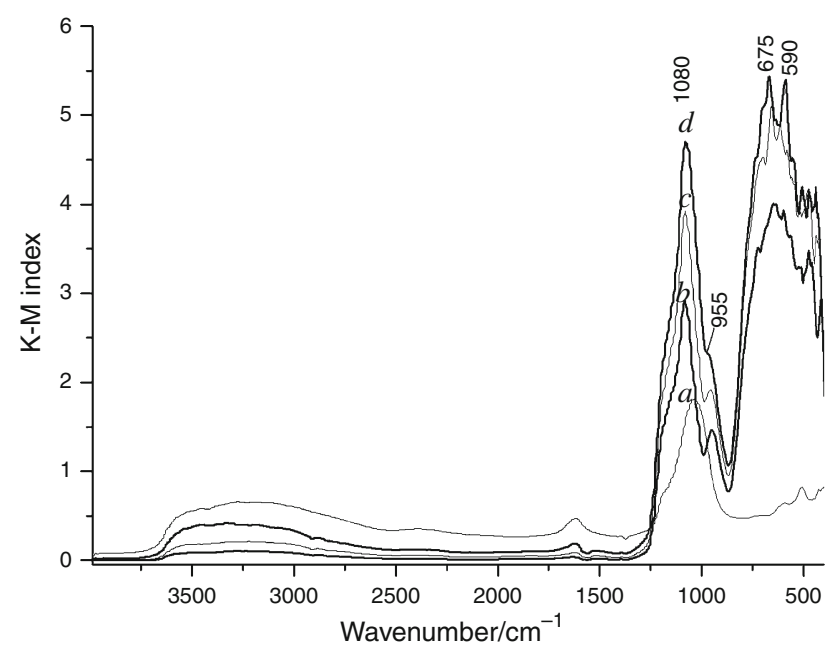

Fig. 6 FTIR spectra for the bulk $\mathrm{ZrP}(a)$ and the milled samples based on $\mathrm{TiO}_{2}$ : $\mathrm{ZrP}$ xerogel air $(b), \mathrm{ZrP}$ xerogel water $(c), \mathrm{ZrP}$ hydrogel $(d)$

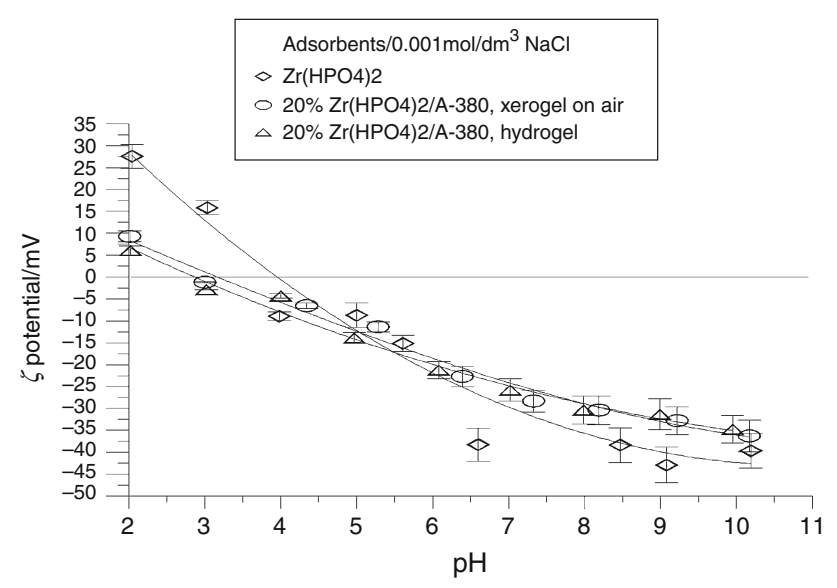

Fig. 7 The $\zeta$ potential-pH dependence for the samples ZrP/A380

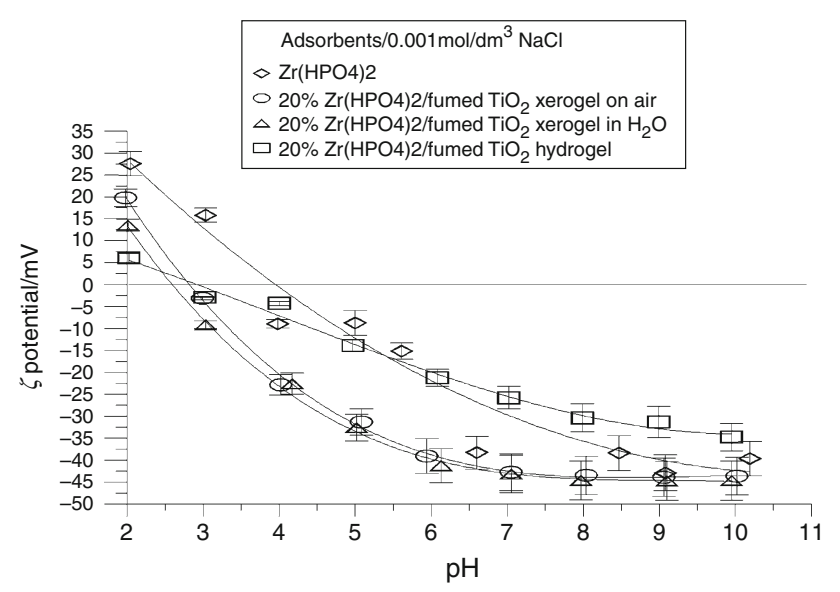

Fig. 8 The $\zeta$ potential-pH dependence for the samples $\mathrm{ZrP} / \mathrm{TiO}_{2}$ mixed (two-component) systems may exhibit isoelectric point values that are intermediate to those of the corresponding pure components [32]. So, in column 4 of Table 2 the $\mathrm{pH}_{\mathrm{iep}}^{\mathrm{ad}}$ values there are presented for the supported samples calculated by the additive rule. From Table 2 one can see that for most deposited samples (except one) $\mathrm{pH}_{\mathrm{iep}}$, determined experimentally, is smaller than that for bulk $\mathrm{ZrP}$ but larger compared with the $\mathrm{pH}_{\text {iep }}^{\text {ad }}$ values. Only for the compositions prepared through milling of $\mathrm{ZrP}$ xerogel with titania (samples 3,4) $\mathrm{pH}_{\text {iep }}$ and $\mathrm{pH}_{\text {iep }}^{\text {ad }}$ coincide. These samples have a minimum value of $\mathrm{pH}_{\text {iep }}$ close to $\mathrm{pH}_{\text {iep }}$ of pure support. The magnitude of difference between $\mathrm{pH}_{\mathrm{iep}}$ and $\mathrm{pH}_{\mathrm{iep}}^{\mathrm{ad}}$ obviously depends on the extent of coverage of support surface with ZrP. Based on this assumption, one can conclude that the surface of titania is covered with $\mathrm{ZrP}$ to the smallest extent. At the same time, the use of nonporous support possessing a maximal specific surface area (namely A380) leads to the increase of $\mathrm{pH}_{\mathrm{iep}}$ of the formed composition and improved coverage of the support surface. The deposition of $\mathrm{ZrP}$ in the form of wet hydrogel brings the same results (samples 5-7). The supported samples prepared using sol-gel procedure display an average effect (samples 8-10).

Surface charge density at the deposited sample/ electrolyte solution interface

Figures 9, 10 show the relationships of surface charge density versus $\mathrm{pH}$ for the electrolyte concentration $0.001 \mathrm{~mol} \mathrm{dm}^{-3}$ for some samples. As one can possibly notice, the surface charge density $\sigma$ decreases with the $\mathrm{pH}$ increase in all cases. However, the surface charge density is rather sharply and uniformly reduced for bulk $\mathrm{ZrP}$. At the same time, this parameter decreases very slowly in the range from $\mathrm{pH}_{\mathrm{pzc}}$ to $\mathrm{pH}=7$ for the silica based samples (Fig. 9). Fast jump of $\sigma$ is observed over this $\mathrm{pH}$ value. It is characteristic of $\mathrm{SiO}_{2} /$ solution system [33]. The course of surface charge density $-\mathrm{pH}$ dependences obtained for the $\mathrm{TiO}_{2}$ based compositions is closer to that for bulk $\mathrm{ZrP}$ (Fig. 10).

On the other hand, the point of zero charge $\mathrm{pH}_{\mathrm{pzc}}$ is approximately equal to 3.45 for bulk $\mathrm{ZrP}$ and all studied deposited samples independent of the nature of support and method of their preparation. The values of $\mathrm{pH}_{\mathrm{pzc}}$ and $\mathrm{pH}_{\mathrm{iep}}$ of the $\mathrm{ZrP}$ sample are very close(within $0.2 \mathrm{pH}$ unit) that may testify that its surface is free of alkali or acid contaminants [34]. The deposited samples of $\mathrm{ZrP}$ on fumed $\mathrm{TiO}_{2}$ show different $\mathrm{pHiep}$ for $\mathrm{ZrP}$ hydrogel deposited on fumed $\mathrm{TiO}_{2}$ is $0.2 \mathrm{pH}$ unit below $\mathrm{pH}_{\mathrm{pzc}}$, whereas for xerogels in air and xerogels in $\mathrm{H}_{2} \mathrm{O}$ is below $\mathrm{pH} p z c 0.65$ and $0.8 \mathrm{pH}$ unit, respectively. This indicate that deposition of $\mathrm{ZrP}$ xerogel in air or in $\mathrm{H}_{2} \mathrm{O}$ on the surface of the samples there appeared groups of acidic character. However, small increase in the 
Table 2 Value of $\mathrm{pH}_{\text {iep }}$ samples of zirconium phosphate $\mathrm{Zr}(\mathrm{HPO} 4)_{2}$ deposited on different supports via different techniques

\begin{tabular}{|c|c|c|c|}
\hline Number & Composition and methods synthesis & $\mathrm{pH}_{\mathrm{iep}}$ & $\mathrm{pH}_{\mathrm{iep}}^{\mathrm{ad}}$ \\
\hline 1 & 2 & 3 & 4 \\
\hline 1. & $\mathrm{Zr}\left(\mathrm{HPO}_{4}\right)_{2}$ bulk, precipitation from $\mathrm{ZrOCl}_{2}$ and $\mathrm{H}_{3} \mathrm{PO}_{4}$ & 3.65 & 3.65 \\
\hline 2. & $20 \mathrm{Zr}\left(\mathrm{HPO}_{4}\right)_{2} / \mathrm{A}-380, \mathrm{MChT}$ of $\mathrm{Zr}\left(\mathrm{HPO}_{4}\right)_{2}$ xerogel on air, $300 \mathrm{rpm} 0.5 \mathrm{~h}$ & 3.35 & 2.43 \\
\hline 3. & $20 \% \mathrm{Zr}\left(\mathrm{HPO}_{4}\right)_{2}$ fumed $\mathrm{TiO}_{2}$, MChT of $\mathrm{Zr}(\mathrm{HPO} 4)_{2}$ xerogel on air, $300 \mathrm{rpm} 0.5 \mathrm{~h}$ & 2.80 & 2.81 \\
\hline 4. & $20 \% \mathrm{Zr}\left(\mathrm{HPO}_{4}\right)_{2} /$ fumed $\mathrm{TiO}_{2}, \mathrm{MChT}$ of $\mathrm{Zr}\left(\mathrm{HPO}_{4}\right)_{2}$ xerogel in $\mathrm{H} 2 \mathrm{O}, 300 \mathrm{rpm} 0.5 \mathrm{~h}$ & 2.62 & 2.81 \\
\hline 5. & $20 \% \mathrm{Zr}\left(\mathrm{HPO}_{4}\right)_{2} / \mathrm{A}-380, \mathrm{MChT}$ of $\mathrm{Zr}\left(\mathrm{HPO}_{4}\right)_{2}$ hydrogel, $300 \mathrm{rpm} 0.5 \mathrm{~h}$ & 3.16 & 2.43 \\
\hline 6. & $20 \% \mathrm{Zr}\left(\mathrm{HPO}_{4}\right)_{2} / \mathrm{A}-50, \mathrm{MChT}$ of $\mathrm{Zr}\left(\mathrm{HPO}_{4}\right)_{2}$ hydrogel, $300 \mathrm{rpm} 0.5 \mathrm{~h}$ & 3.77 & 2.57 \\
\hline 7. & $20 \% \mathrm{Zr}\left(\mathrm{HPO}_{4}\right)_{2} /$ fumed $\mathrm{TiO}_{2}, \mathrm{MChT}$ of $\mathrm{Zr}\left(\mathrm{HPO}_{4}\right)_{2}$ hydrogel, $300 \mathrm{rpm} 0.5 \mathrm{~h}$ & 3.20 & 2.81 \\
\hline 8. & $10 \% \mathrm{Zr}\left(\mathrm{HPO}_{4}\right)_{2} / \mathrm{SiO}_{2}$, sol-gel from $\mathrm{ZrOCl}_{2}+\mathrm{TEOS}$ & 2.98 & 2.73 \\
\hline 9. & $20 \% \mathrm{Zr}\left(\mathrm{HPO}_{4}\right)_{2} / \mathrm{SiO}_{2}$, sol-gel from $\mathrm{ZrOCl}_{2}+$ TEOS & 2.98 & 2.73 \\
\hline 10. & $20 \% \mathrm{Zr}\left(\mathrm{HPO}_{4}\right)_{2} / \mathrm{SiO}_{2}$, sol-gel from $\mathrm{ZrOCl}_{2}+$ TEOS and $\mathrm{HTT}$ of hydrogel $200{ }^{\circ} \mathrm{C} 3 \mathrm{~h}$ & 2.98 & 2.73 \\
\hline
\end{tabular}

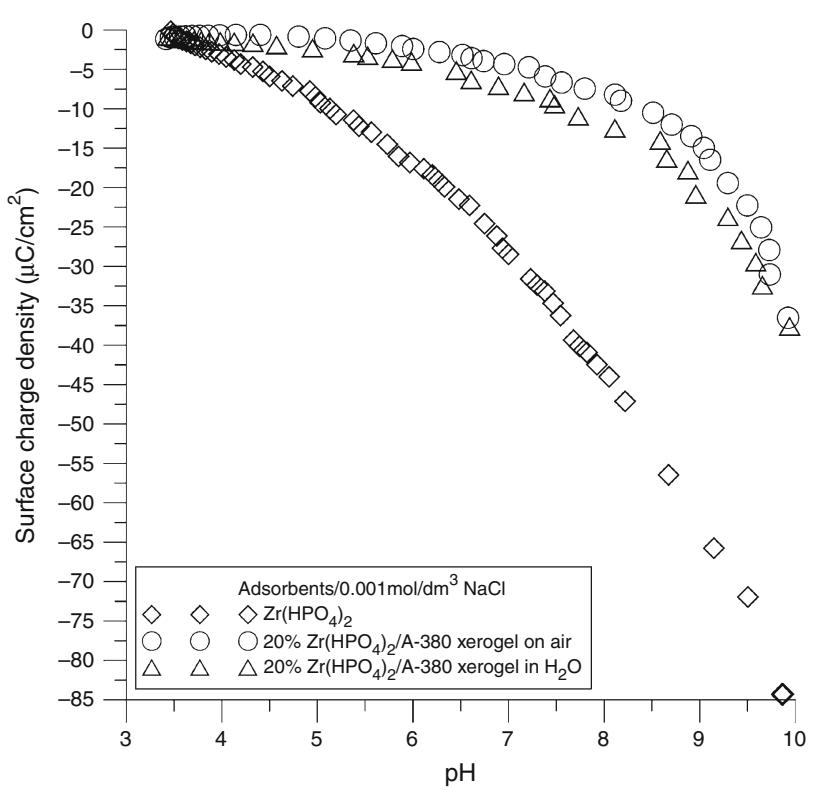

Fig. 9 The surface charge density-pH dependence for the samples $\mathrm{ZrP} / \mathrm{A} 380$

surface charge in the sample of $\mathrm{ZrP} /$ fumed $\mathrm{TiO}_{2}$ xerogel/ electrolyte interface indicated that surface concentration of these groups is lower than that for sample prepared in $\mathrm{H}_{2} \mathrm{O}$. As mentioned above, the surface charge density as a function $\mathrm{pH}$ of $\mathrm{ZrP}$ deposited on A-380 shows similar characteristic to that of the silica/electrolyte system. The comparison of $\mathrm{pH} p z c$ and $\mathrm{pHiep}$ for these systems is very difficult because the slope of surface charge as a function of $\mathrm{ZrP} / \mathrm{A}-380$ samples is very low (as in the case of silica). However, the shift of $\mathrm{pH}_{\text {iep }}$ shows that for these samples on the surface, the groups with acidic properties also appear.

Therefore, it can be assumed that in the deposited samples $\mathrm{ZrP}$ itself influences on the surface charge more than a support.

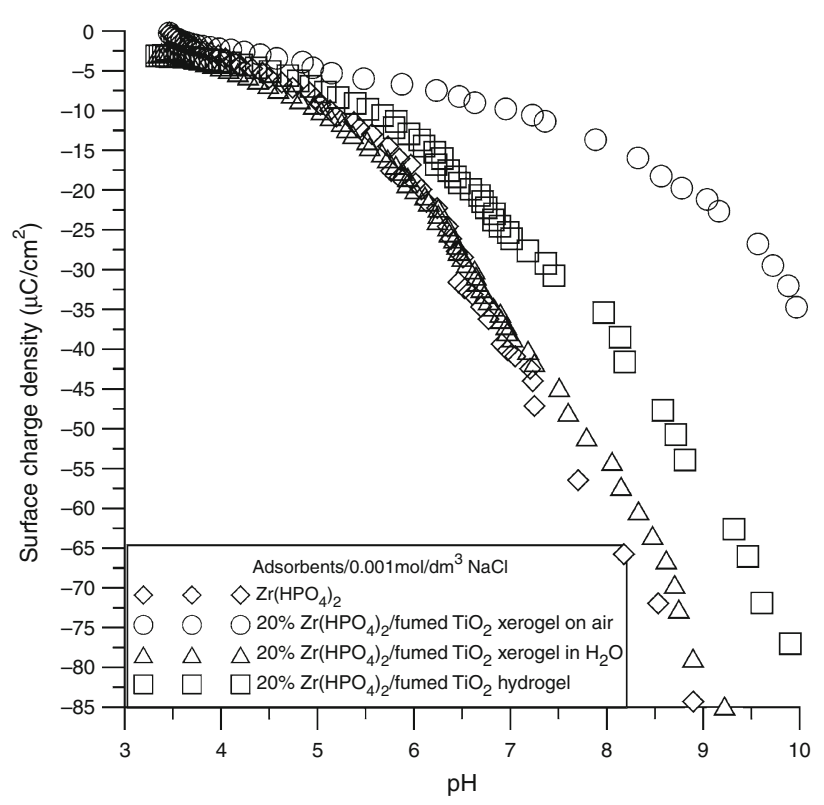

Fig. 10 The surface charge density-pH dependence for the samples $\mathrm{ZrP} / \mathrm{TiO}_{2}$

\section{Conclusions}

The synthesis of the zirconium phosphate/oxide support compositions was carried out using two procedures: joint milling of $\mathrm{ZrP}$ with the support and co-precipitation of $\mathrm{ZrP}$ and silica during the sol-gel process. Deposited mesomacroporous or micro-mesoporous samples are formed using the mechanochemical and sol-gel methods, respectively. Amorphous zirconium phosphate located in pores interacts with varying force with the surface of supports depending on porous structure. The degree of support surface coverage is determined by nature of support and methods of zirconium phosphate deposition. The zeta potential of supported samples based on titania has a value 
close to the zeta potential of pure support while the samples prepared via deposition of zirconium hydrogel on aerosils possess the zeta potential equal to that for bulk zirconium phosphate. At the same time, the surface charge density of all supported samples is exceptionally determined by that of zirconium phosphate.

Acknowledgements This study was supported by the European Community under a Maria Curie International Research Staff Exchange Scheme (IRSES), Project No 230790.

Open Access This article is distributed under the terms of the Creative Commons Attribution Noncommercial License which permits any noncommercial use, distribution, and reproduction in any medium, provided the original author(s) and source are credited.

\section{References}

1. Yaroslavtsev AB. Ion exchange in the inorganic sorbents. Russ Chem Rev. 1997;66:579-96.

2. Naushad Mu. Inorganic and composite ion exchange materials and their applications. Ion Exch Lett. 2009;2:1-14.

3. Amphlett CB. Inorganic Ion Exchanger. Amsterdam: Elsevier; 1964.

4. Clearfield A. Inorganic ion exchanger materials. Boca Raton: CRC Press; 1982.

5. Clearfield A, Bortun AI, Khainakov SA, et al. Spherically granulated titanium phosphate as exchanger for toxic heavy metals. Waste Manag. 1998;18:203-10.

6. Corma A. Solid acid catalysts. Curr Opinion Solid State Mater Sci. 1997;2:63-75.

7. Alberti G, Casciola M. Solid state protonic conductors, present main applications and future prospects. Solid State Ionics. 2001;145:3-16.

8. Miyoshi H, Ieyasu M, Yoshino T, Kourai H. Photochemical properties and surface characterization of silver-loaded zirconium phosphate. J Photochem Photobiol A. 1998;112:239-44.

9. Pan BC, Zhang QR, Zhang WM, Pan BJ, Du W, Lv L, Zhang QJ, $\mathrm{Xu} Z \mathrm{ZW}$, Zhang QX. Highly effective removal of heavy metals by polymer-based zirconium phosphate: a case study of lead ion. J Colloid Interface Sci. 2007;310:99-105.

10. Alberti G, Casciola M, Capitani D, Donnadio A, Narducci R, Pica M, Sganappa M. Novel nafion-zirconium phosphate nanocomposite membranes with enhanced stability of proton conductivity at medium temperature and high relative humidity. Electrochim Acta. 2007;52:8125-32.

11. Zhang QR, Du W, Pan BC, Pan BJ, Zhang WM, Zhang QJ, Xu $\mathrm{ZW}$, Zhang QX. A comparative study on $\mathrm{Pb}^{2+}, \mathrm{Zn}^{2+}$ and $\mathrm{Cd}^{2+}$ sorption onto zirconium phosphate supported by a cation exchanger. J Hazard Mater. 2008;152:469-75.

12. So LV. Investigations on the silica gel supported form of microcrystalline zirconium phosphate ion-exchanger and its applications in chemical separations. 1. Preparation, ion-exchange properties and stability of Si-ZrP. J Radioanal Nucl Chem. 1986;99:17-30.

13. Szirtes L. Zirconium phosphates on silica matrix. Solid State Ionics. 1993;61:145-7.

14. Alberti G, Casciola M, Constantiono U, Peraio A, Rega T. Proton-conducting solid dispersions of silica and zirconium phosphate pyrophosphate. J Mater Chem. 1995;5:1809-12.

15. Nagata N, Kubota LT, Bueno MIMS, Peralta-Zamora PG. Adsorption parameters of $\mathrm{Cd}(\mathrm{II}), \mathrm{Pb}(\mathrm{II})$, and $\mathrm{Hg}(\mathrm{II})$ on zirconium(IV) phosphate chemically grafted onto silica gel surface. J Colloid Interface Sci. 1998;200:121-5.
16. Khalil LB, Attia AA, El-Nabarawy T. Modified Silica for the extraction of cadmium(II), copper(II) and zinc(II) ions from their aqueous solutions. Adsorp Sci Technol. 2001;19:511-23.

17. Alberti G, Cavalaglio S, Marmottini F, Matusek K, Megyeri J, Szirtes L. Prepation of a composite $\gamma$-zirconium phosphate-silica with large specific surface and its first characterization as acid catalyst. Appl Catal A. 2001;218:219-28.

18. Pavelec B, Murcia-Mascaros S, Fierro JLG. Surface and structural featuresof Pt/Pd-loaded mesoporous silica-delaminated zirconium phosphate systems. Langmuir. 2002;18:7953-63.

19. Bellezza F, Cipiciani A, Costantino R, Negozio E. Zirconium phosphate and modified zirconium phosphates as supports of lipase. Preparation of the composites and activityof the supported of enzyme. Langmuir. 2002;18:8737-42.

20. Matoso E, Kubota LT, Cadore S. Use of silica gel chemically modified with zirconium phosphate for preconcentration and determination of lead and copper by flame atomic absorption spectrometry. Talanta. 2003;60:1105-11.

21. Zhang J, Ma Z, Jiao J, Yin H, Yan W, Hagaman EW, Yu J, Dai S. Surface functionalization of mesoporous silica SBA-15 by liquidphase grafting of zirconium phosphate. Micropor Mesopor Mater. 2010;129:200-9.

22. Nagy LG, Török G, Vaida N, Gerlei I. Preparation of zirconium phosphate on support material and its application for the sorption of some radioions. J Radioanal Nucl Chem. 1980;58:215-20.

23. El-Sourougy MR, Zaki EE, Aly HF. Transport characteristics of ceramic supported zirconium phosphate membrane. J Membr Sci. 1997;126:107-13.

24. Glipa X, Leloup J-M, Jones DJ, Roziere J. Enhancement of the protonic conductivity of $\alpha$-zirconium phosphates by composite formation with alumina and silica. Solid State Ionics. 1997;97: 227-32.

25. Sydorchuk V, Khalameida S, Zazhigalov V, Skubiszewska-Zięba J, Leboda R, Wieczorek-Ciurowa K. Influence of mechanochemical activation in various media on structure of porous and non-porous silicas. Appl Surf Sci. 2010;257:446-50.

26. Sydorchuk V, Khalameida S, Skubiszewska-Zięba J, Leboda R. Synthesis and structure of AMP/oxide support. J Therm Anal Calorim. 2011;103:257-65.

27. Trach Yu, Sydorchuk V, Makota O, Khalameida S, Leboda R, Skubiszewska-Zięba J, Zazhigalov V. Synthesis, physical-chemical and catalytic properties of mixed compositions $\mathrm{Ag} / \mathrm{H}_{3} \mathrm{PMo}_{12}$ $\mathrm{O}_{40} / \mathrm{SiO}_{2} \mathrm{~J}$ Therm Anal Calorim. 2011. doi: 10.1007/s10973011-1430-z.

28. Tarafdar A, Panda AB, Pradhan NC, Pramanik P. Synthesis of spherical mesostructured zirconium phosphate with acidic properties. Micropor Mesopor Mater. 2006;95:360-5.

29. Jung J-H, Sohn H-J. Preparation and characterization of mesoporous zirconium phosphates from alkyl phosphates. Micropor Mesopor Mater. 2007;106:49-55.

30. Kosmulski M. pH-dependent surface charging and points of zero charge. IV. Update and new approach. J Colloid Interface Sci. 2009;337:439-48.

31. Jolivet JP. Metal oxide chemistry and synthesis. From solution to solid state. New York: John Wiley \& Sons; 2000.

32. Jara AA, Goldberg S, Mora ML. Studies of the surface charge of amorphous alumiosilicates using surface complexation models. J Colloid Interface Sci. 2005;292:160-70.

33. Janusz W. Electrical double layer at the metal oxide/electrolyte interface. In: Hsu P, editor. Surfactant Sci, vol. 85. New York: M.Dekker; 1999. p. 135-206.

34. Zalac S, Kallay N. Application of mass titration to the point zero of charge determination. J Colloid Interface Sci. 1992;149: 233-40. 